\title{
Influência do estádio fenológico e da idade dos trifólios de soja na infecção de Phakopsora pachyrhizi
}

\author{
Gleiber Quintão Furtado ${ }^{1}$, Silvio A.M. Alves ${ }^{1}$, Luciana C. Carneiro ${ }^{1}$, Claudia V. Godoy² \& Nelson Sidnei \\ Massola Júnior ${ }^{1}$
}

${ }^{1}$ Departamento de Entomologia, Fitopatologia e Zoologia Agrícola, ESALQ, Universidade de São Paulo, 13418-090, Piracicaba, SP, Brasil; ${ }^{2}$ Embrapa Soja, 86001-970, Londrina, PR, Brasil

Autor para correspondência: Gleiber Quintão Furtado, e-mail: gleiberfurtado@gmail.com

\begin{abstract}
RESUMO
Objetivou-se detectar a influência do estádio fenológico e da idade da folha de soja na infecção por Phakopsora pachyrhizi, agente causal da ferrugem asiática (FA). Plantas das cultivares BRS 154 e BRS 258 foram inoculadas, com suspensão de $10^{5}$ urediniósporos/mL, nos estádios fenológicos $\mathrm{V}_{3}, \mathrm{R}_{1}$ e $\mathrm{R}_{5}$. Após 24 horas de câmara úmida, as plantas foram acondicionadas em condições de casa de vegetação por 20 dias. Avaliou-se o período latente médio (PLM) e a severidade. Para a avaliação da suscetibilidade de trifólios à FA utilizou-se a cultivar BRS $154\left(\mathrm{~V}_{5}\right)$. A inoculação foi realizada nos quatro primeiros trifólios. Aos 15 dias após a inoculação, os folíolos foram avaliados quanto à severidade, tamanho médio de lesão e freqüência de infecção. O estádio das plantas de soja não influenciou no PLM. As cultivares BRS 154 e BRS 258 tiveram PLM de 8 e 9 dias, respectivamente. As cultivares não se diferenciaram quanto à severidade da doença. Não houve diferença de severidade nos estádios $\mathrm{V}_{3}$ e $\mathrm{R}_{1}$, porém, os valores de severidade nesses estádios foram superiores ao valor de severidade no estádio $\mathrm{R}_{5}$, na avaliação realizada 8 dias após a inoculação. Em relação à suscetibilidade de folhas, o trifólio mais velho apresentou maiores valores de doença.
\end{abstract}

Palavras-chave: Glycine max, ferrugem asiática, estádios de inoculação.

\begin{abstract}
Influence of soybean phenological stage and leaflets age on infection by Phakopsora pachyrhizi

This work was conducted to study the influence of soybean growth stage and leaf age on the infection of Phakopsora pachyrhizi, the soybean rust pathogen. Soybean plants (cv. BRS 154 and BRS 258) at the $\mathrm{V}_{3}, \mathrm{R}_{1}$ and $\mathrm{R}_{5}$ growth stages were inoculated with a $1 \times 10^{5}$ urediniospores per $\mathrm{mL}$ suspension. After a period of 24 hours in dew chambers, all plants were removed from the chambers and placed under greenhouse conditions for 20 days. Mean latent period (PLM) and disease severity were estimated. The susceptibility of trifoliate leaves to soybean rust was estimated on cv. BRS 154 at the growth stage $\mathrm{R}_{5}$. Pathogen inoculation was done at the first four trifoliate leaves. Fifteen days after inoculation, leaflets of each trefoil were evaluated for disease severity, lesion mean size and infection frequency. Plants' growth stage did not influence the PLM. Cultivars BRS 154 and BRS 258 presented PLM of 8 and 9 days, respectively. There was no difference in disease severity at the growth stages $\mathrm{V}_{3}$ and $\mathrm{R}_{1}$, but those values were higher than at the $\mathrm{R}_{5}$ growth stage, 8 days after inoculation. The oldest trefoil showed the highest disease values.
\end{abstract}

Keywords: Glycine max, Asian soy-bean rust, stages of inoculation.

A ferrugem asiática (FA) da soja [Glycine max (L.) Merr.] é causada pelo fungo Phakopsora pachyrhizi Syd. \& P. Syd, originário da região australasiana. No Brasil, as primeiras epidemias ocorreram a partir de 2001. Em 2002 a doença já estava disseminada em $60 \%$ da área de cultivo do país e $90 \%$ no ano seguinte. As perdas, US\$ 125 milhões na safra de 2001/2002, alcançaram mais de US\$ 1 bilhão em 2002/2003 e mais de 2 bilhões em 2003/2004 (Yorinori et al., 2005). O processo de infecção dos urediniósporos de P. pachyrhizi compreende diversos passos distintos: adesão na superfície do hospedeiro, germinação, formação do apressório, penetração através da cutícula, invasão e crescimento das hifas no tecido hospedeiro (Bonde et al., 1976; Koch et al., 1983; Marchetti et al., 1976; Koch \& Hoppe, 1988).
Experimentos conduzidos no Brasil, com a cultivar BRS 154, mostraram que urediniósporos de $P$. pachyrhizi necessitaram de no mínimo 6 e no máximo 24 horas de água livre para infectar, com faixa de temperatura ideal entre 15 e $25^{\circ} \mathrm{C}$ e temperatura ótima de $23^{\circ} \mathrm{C}$. O período latente variou conforme a temperatura, sendo de 30, 10 e 12 dias para as temperaturas de 10,20 e $28^{\circ} \mathrm{C}$, respectivamente (Alves et al., 2006). Plantas de soja severamente infectadas apresentam desfolha precoce, comprometendo a formação, o enchimento de vagens e o peso final de grãos. Quanto mais cedo ocorrer a desfolha, menor será o tamanho do grão e, conseqüentemente, maior a perda de rendimento e de qualidade (Yang et al., 1991). O presente estudo teve como objetivo avaliar a influência do estádio fenológico e da idade da folha de soja na infecção de P. pachyrhizi. 
O isolado utilizado foi obtido em plantas de soja infectadas naturalmente, provenientes do campo experimental do Setor de Fitopatologia da ESALQ/USP, Piracicaba, SP, e multiplicado na cultivar BRS 154, sendo os esporos armazenados periodicamente em nitrogênio líquido, conforme metodologia proposta por Furtado et al. (2008).

Para verificar a influência do estádio fenológico na reação à ferrugem, plantas de soja das cultivares BRS $154 \mathrm{e}$ BRS 258 foram inoculadas nos estádios $\mathrm{V}_{3}, \mathrm{R}_{1}$ e $\mathrm{R}_{5}$ (Fehr \& Caviness, 1977). A obtenção das plantas nesses três estádios foi conseguida por meio de semeaduras em três datas sucessivas intercaladas por 20 dias. Foram utilizados vasos de plástico de $10 \mathrm{~L}$ com a mistura de terra argilosa, areia e esterco (2:1:2). As plantas foram inoculadas com suspensão de $10^{5}$ urediniósporos $/ \mathrm{mL}$ em todos os trifólios até o ponto de escorrimento. Posteriormente foram acondicionadas em câmara úmida no escuro a $20 \pm 2^{\circ} \mathrm{C}$ por 24 horas. Após esse período as plantas permaneceram em condições de casa de vegetação por 20 dias.

Foram avaliados o período latente médio (PLM), que corresponde ao período em dias após a inoculação até o aparecimento de $50 \%$ das lesões esporulando, e a severidade, com auxílio da escala diagramática proposta por Godoy et al. (2006). A avaliação foi realizada em todos trifólios que receberam a inoculação. A unidade amostral para as avaliações foram os três folíolos de cada trifólio sendo utilizada a média dos valores como o valor de cada repetição. Para obtenção do PLM as plantas foram examinadas diariamente no mesmo horário. A severidade foi estimada aos 8 e 16 dias após a inoculação (d.a.i.). As plantas de ambas as cultivares que foram inoculadas no estádio fenológico $V_{3}$ não foram reavaliadas na segunda avaliação em decorrência da desfolha.

$\mathrm{O}$ delineamento foi inteiramente casualizado, em esquema fatorial de 3 ou 2 (estádios fenológicos) x 2 (cultivares), com 7 repetições. Cada repetição consistiu de um vaso com 2 plantas. Para a avaliação da influência da idade da folha de plantas de soja à FA utilizaram-se plantas da cultivar BRS 154, no estádio fenológico $\mathrm{V}_{5}$. A inoculação foi realizada na superfície adaxial dos quatro primeiros trifólios expandidos com uma suspensão de $10^{5}$ urediniósporos $/ \mathrm{mL}$. No sentido base-ápice, a idade do trifólio foi denominada, 1, 2, 3 e 4. Após a inoculação as plantas foram mantidas em câmara úmida, por 24 horas, sob temperatura de $23^{\circ} \mathrm{C}$, no escuro. Posteriormente, as plantas permaneceram sob fotoperíodo de 12 horas de luz e temperatura entre $23-32^{\circ} \mathrm{C}$

Aos 15 d.a.i., os folíolos foram destacados e avaliados quanto à severidade, tamanho médio de lesão e freqüência de infecção, por meio de fotografia digital, utilizando os programas Paint Shop Pro e Image Tool (Alves et al., 2005). $\mathrm{O}$ delineamento foi inteiramente casualizado, com cinco repetições, sendo cada repetição constituída por um vaso com uma planta. A unidade amostral para as avaliações foram os três folíolos de cada trifólio sendo utilizada a média dos valores como o valor de cada repetição. A média da porcentagem de germinação dos urediniósporos utilizados nas inoculações foi $36 \%$, na avaliação realizada em agar-água. O estágio fenológico das plantas de soja não influenciou no PLM da ferrugem. Entretanto, essa variável diferiu em função das cultivares, com diferença de um dia entre eles. As plantas da cultivar BRS 154 e BRS 258 tiveram PLM de 8 e 9 dias, respectivamente, em condições de casa de vegetação com temperatura variando entre $22 \mathrm{e}$ $32^{\circ} \mathrm{C}$ (Tabela 1).

TABELA 1 - Período latente médio (dias) de Phakopsora pachyrhizi em função da cultivar e do estádio fenológico de plantas de soja

\begin{tabular}{cccc}
\hline \hline & \multicolumn{3}{c}{ Estádio Fenológico } \\
\cline { 2 - 4 } & $\mathbf{V}_{\mathbf{3}}$ & $\mathbf{R}_{\mathbf{1}}$ & $\mathbf{R}_{\mathbf{5}}$ \\
\hline BRS 154 & 8 & 8 & 8 \\
BRS 258 & 9 & 9 & 9 \\
\hline
\end{tabular}

Alves et al. (2006) ao estudar o efeito da temperatura sobre o PLM da ferrugem da soja para a cultivar BRS 154, observaram, na temperatura de $22,5{ }^{\circ} \mathrm{C}, 9$ dias de duração do PLM. Resultados obtidos por Balardin et al. (2005), em cultivares suscetíveis inoculadas após o florescimento e mantidas em temperaturas variando entre 22 e $30^{\circ} \mathrm{C}$, apresentaram início da formação das lesões entre 7 e 9 dias.

Melching etal.(1988), em estudos com plantas de soja da cultivar Wayne, encontraram menor período latente da FA em plantas que apresentavam, no momento da inoculação, idade entre 15 e 20 dias (PLM de 8 dias) do que nas plantas com 37-42 dias (PLM de 10 dias). Estes resultados diferem, portanto, daqueles encontrados no presente trabalho, nos quais as cultivares BRS 154 e BRS 258 não apresentaram influência do estádio de desenvolvimento da planta sobre o PLM da FA.

O estádio fenológico das plantas é um importante fator que afeta diretamente o desenvolvimento das doenças. Dependendo da doença, a suscetibilidade do tecido do hospedeiro pode aumentar ou decrescer ao longo do tempo. Welty \& Baker (1992) compararam a suscetibilidade de plantas de centeio perene à infecção de Puccinia graminis subsp. graminicola e observaram que plantas com oito semanas de idade eram mais suscetíveis que plantas com 14 semanas. O mesmo comportamento, maior suscetibilidade de plantas mais novas, foi observado para os patossitemas: fumo - Peronospora tabacina (Reuveni et al., 1986) e alface - Bremia lactucae (Dickinson \& Crute, 1974). Entretanto, plantas de feijão mostraram maior suscetibilidade a Uromyces phaseoli e TMV (Tobacco Mosaic Virus) em folhas mais desenvolvidas em relação às menos desenvolvidas (Schein, 1965). Nas avaliações 
de severidade da FA não houve interação estatística, ao nível de $5 \%$ de probabilidade, entre os fatores fenologia e cultivares, ou seja, as cultivares apresentaram o mesmo comportamento à FA nos diferentes estádios fenológicos. No entanto, a fenologia influenciou a suscetibilidade das cultivares à FA.

As severidades da FA, aos oito d.a.i, em plantas de soja nos estádios fenológicos $\mathrm{V}_{3}$ e $\mathrm{R}_{1}$ não se diferenciaram estatisticamente, porém, essas foram superiores à severidade das plantas no estádio $\mathrm{R}_{5}$ (Figura $1 \mathrm{~A}$ ). Na avaliação realizada aos 16 d.a.i., a severidade de FA em plantas nos estádios $R_{1}$ e $\mathrm{R}_{5}$ foram estatisticamente iguais (Figura 1B). Possivelmente, esse resultado observado na segunda avaliação se deva a ocorrência de desfolha em plantas no estádio $R_{1}$. Estes resultados mostram que o estádio de desenvolvimento reprodutivo $\mathrm{R}_{5}$ é menos favorável a ocorrência de $\mathrm{FA}$ em relação aos demais estádios fenológicos avaliados nesse trabalho e corroboram com os estudos realizados por Melching et al. (1988) onde foi observada uma maior eficiência de infecção de $P$. pachyrhizi em plantas de soja mais novas do que em plantas mais velhas. As porcentagens de infecção de plantas com 15 e 42 dias de idade foram 5\% e $1 \%$, respectivamente.

Em condições de campo a incidência da FA é observada de forma mais freqüente a partir do florescimento das plantas. Em contraste, no presente trabalho observou-se, já no estádio vegetativo, alta suscetibilidade ao patógeno. Isso pode ser explicado por diferentes fatores que atuam conjuntamente. No campo, nos plantios iniciais, quando as plantas estão no estádio vegetativo, a população do patógeno ainda se encontra em baixos níveis, os quais aumentam simultaneamente com o ciclo da cultura. Desta forma, na fase reprodutiva da cultura, a maior concentração de esporos propicia maiores taxas de infecção e, conseqüentemente, maior severidade da FA. Esse fato foi observado em regiões do Mato Grosso, onde a semeadura de soja era feita de forma contínua ao longo do ano, e a incidência da doença ocorria a partir do período vegetativo durante a safra (Siqueri, 2005). Outros fatores estão relacionados ao fechamento das entreslinhas na lavoura, que contribui para ocorrência de períodos maiores de molhamento, favoráveis a infecção e também a menor radiação solar que atua de forma significativa na sobrevivência de urediniósporos de $P$. pachyrhizi (Isard et al., 2006). Em relação à suscetibilidade dos trifólio de soja à FA, observou-se efeito estatisticamente significativo entre a idade dos mesmos e as variáveis relacionadas à doença, freqüência de infecção, severidade e tamanho médio de lesão (Figura 2).

Para todas variáveis avaliadas, o trifólio mais velho (trifólio 1) apresentou maiores valores de doença. A amplitude dos valores obtido na folha 1 e 4 para freqüência de infecção, severidade e tamanho de lesão foram 5,4$0,96,1,97-0,22$ e $0,34-0,21$, respectivamente. No entanto, resultados diferentes foram obtidos por Melching et al. (1988) que observaram, para a variável freqüência de infecção, valores maiores para os trifólios mais novos independente do estádio de desenvolvimento das plantas de soja. Os resultados apresentados por Melching et al. (1988), bem como aqueles referentes ao PLM, são diferentes dos resultados obtidos no presente trabalho e uma possível explicação são as diferentes cultivares de soja e isolados do fungo utilizados em cada um dos trabalhos. Martins et al. (2007), ao testarem a resistência de 68 cultivares de soja por meio do PLM, discriminaram dois grupos de genótipos, parcialmente resistentes e suscetíveis. Desta forma, a interação patógeno-planta parece apresentar características específicas, em relação ao PLM, fenologia e idade da folha em função do isolado do patógeno e da
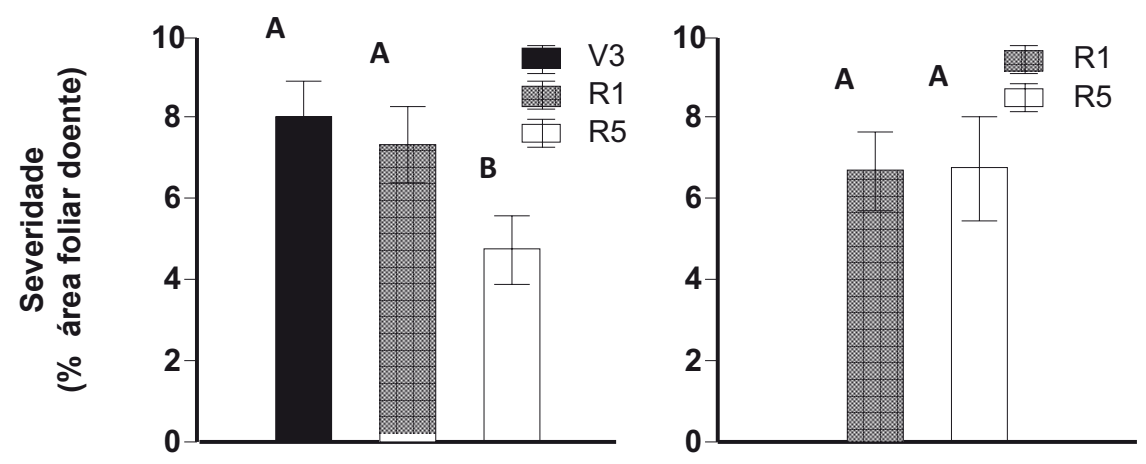

FIGURA 1 - A. Influência da fenologia de plantas de soja sobre a severidade da ferrugem da soja aos 8; B. 16 dias após a inoculação. Tratamentos com letras iguais não diferem diferem estatisticamente pelo teste de Tukey $(\mathrm{P}<0,05)$. Barra de erro representa erro padrão da média. 

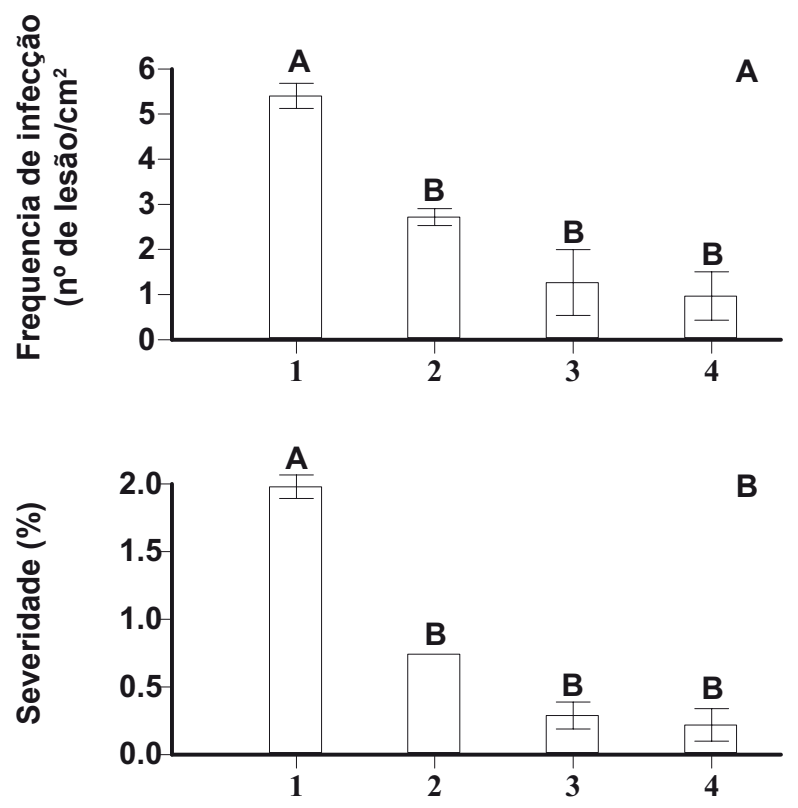

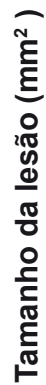

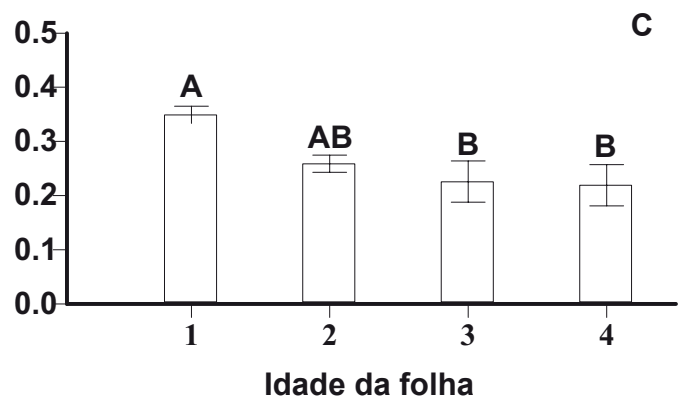

FIGURA 2 - A. Influência da idade da folha de soja cultivar BRS 154 na freqüência de infecção $\left(\mathrm{n}^{\circ}\right.$ de lesões/ $\left.\mathrm{cm}^{2}\right)$; B. na severidade; C. no tamanho de lesão de P. pachyrhizi. Os tratamentos com as mesmas letras não diferem estatisticamente pelo teste de Tukey $(\mathrm{P}<0,05)$. Barra de erro representa o erro padrão da média. A idade do trifólio está denominada de 1 a 4 , sendo 1 o mais velho e 4 o mais novo.

cultivar utilizada. A maior suscetibilidade das folhas mais velhas juntamente com maiores períodos de molhamento proporcionados pelo micro-clima e menor irradiação nas folhas baixeiras das plantas de soja podem ser responsáveis pelo desenvolvimento da doença no sentido base-ápice das plantas de soja, em condições de campo.

\section{REFERÊNCIAS BIBLIOGRÁFICAS}

Alves SAM, Carneiro LC, Furtado GQ, Bergamin Filho A (2005) Método preciso para quantificação de ferrugem asiática da soja. Fitopatologia Brasileira 38:461.

Alves SAM, Furtado GQ, Bergamin Filho A (2006) Influência das condições climáticas sobre a ferrugem da soja. In: Zambolim L
(Ed.) Ferrugem asiática da soja. Viçosa MG. Suprema Gráfica e Editora. pp. 37-59.

Balardin RS, Navarini L, Dallagnol LJ (2005) Epidemiologia da ferrugem da soja. In: Julliatti FC, Polizel AC, Hamawaki OT (Eds.) I Workshop Brasileiro sobre a ferrugem asiática. Uberlândia MG. EDUFU. pp. 39-50.

Bonde MR, Melching JS, Bromfield KR (1976) Histology oh the suscept-pathogen relationship between Glycine max and Phakopsora pachyrhizi. Phytopathology 66:1290-1294.

Dickinson CH, Crute JR (1974) The influence of seedling age and development on the infection of lettuce by Bremia lactucae. Annual Applied of Bioloy 76:49-61.

Fehr WR, Caviness CE (1977) Stages of Soybean Development. Special Reporter 80. Cooperative Extension Service. Ames IA. Iowa State University.

Furtado GQ, Alves SAM, Czermainski ABC, Massola Júnior NS (2008) Preservation of Phakopsora pachyrhizi uredospores. Journal of Phytopathology 156:62-64.

Godoy CV, Koga LJ, Canteri MG (2006) Diagrammatic scale for assessment of soybean rust severity. Fitopatologia Brasileira 31:63-68.

Isard SA, Miles MR, Hartman GL, Russo JM, De Wolf ED, Morel W (2006) The effect of solar irradiance on the mortality of Phakopsora pachyrhizi urediniosporos. Plant Disease 90:941945.

Koch E, Ebrahim-Nesbat F, Hoppe HH (1983) Light and electron microscopoic studies on the development of soybean rust (Phakopsora pachyrhizi Syd.) in susceptible soybean leaves. Phytopathologische Zeitschrift 106:302-320.

Koch E, Hoppe HH (1988) Development of infection structures by the direct-penetrating soybean rust fungus (Phakopsora pachyrhizi Syd.) on artificial membranes. Journal of Phytopathology 22:232244.

Martins JAS, Juliatti FC, Santos VA, Polizel AC, Juliatti FC (2007) Período latente e uso de análise de componentes principais para caracterizar a resistência parcial à ferrugem da soja. Summa Phytopathologica 33:364-371.

Marchetti MA, Melching JS, Bromfield KR (1976) The effects of temperature and dew period on germination and incfetion by uredospores of Phakopsora pachyrhizi. Phythopatology 66:461463

Melching JS, Dowler WM, Koogle DL, Royer MH (1988) Effect of plant age on suscetibility of soybean to soybean rust. Canadian Journal of Plant Pathology 10:30-35.

Reuveni M, Tuzuns S, Cole JS, Siegel MR, Kué J (1986) The effects of plant age position on the suscetibility of tobacco to blue mold caused by Peronospora tabacina. Phytopathology 76:455458.

Siqueri FV (2005) Ocorrência da ferrugem asiática (Phakopsora pachyrhizi) no estado do Mato Grosso - safra 2004/2005. In: Juliatti FC, Polizel AC, Hamawaki OT (Eds.) I Workshop Brasileiro sobre a ferrugem asiática. Uberlânida MG. EDUFU. pp. 93-100.

Schein RD (1965) Age-correlated in suscetibility of bean leaves to Uromyces phaseoli and Tobaco Mosaic Virus. Phytopathology 55:455-457.

Welty RE, Barker RE (1992) Evaluation of resistance to stem rust 
G.Q. Furtado et al.

in perennial ryegrass grown in controlled and field conditions. Plant Disease 76:637-641.

Yang XB, Tschanzat AT, Dowler WM, Wang TC (1991) Development of yield loss models in relation to reductions of components of soybean infected with Phakopsora pachyrhizi.
Journal of Phytopathology 81:1420-1426.

Yorinori JT, Paiva WM, Frederick RD, Costamilan LM, Bertagnolli PF, Hartman GE, Godoy CV, Nunes JJR (2005) Epidemics of soybean rust (Phakopsora pachyrhizi) in Brazil and Paraguay from 2001 to 2003. Plant Disease 89:675-677.

Recebido 15 Setembro 2008 - Aceito 7 Abril 2009 - TPP 8111 Editor Associado: Nilceu R.X. Nazareno 